\title{
XXVII. International Conference on Coordination and Bioinorganic Chemistry (27th ICCBIC), June 2019, Slovakia
}

\author{
Peter Segla ${ }^{1}$. Ján Pavlik ${ }^{1} \cdot$ Miroslav Tatarko $^{1} \cdot$ Marian Valko $^{2}$
}

Received: 22 June 2020 / Accepted: 24 June 2020 / Published online: 21 July 2020

(c) Institute of Chemistry, Slovak Academy of Sciences 2020

International Conference on Coordination and Bioinorganic Chemistry has been organized biennially since 1964 . This year it hosted 68 scientists from 19 countries all over the world and 37 scientists from Slovakia (Fig. 1). During the conference, 82 lectures were given (out of them 25 in the "Young Scientist" section) and 23 posters were presented. That the future of coordination and bioinorganic chemistry is nothing to be worried about is corroborated by participation of 40 scientists younger than thirty years.

Traditionally, the lectures have been divided into four sections. In the section A, "Electron, molecular and crystal structure" Prof. Leroy Cronin (UK) gave a very inspiring plenary lecture called Exploring the bio-inorganic driven origins of life. The section B "Solution and Solid State Reactivity" was open by Prof. Roman Boča (Slovakia), who spoke about Open problems in the single ion magnets. Prof. Gábor Molnár (France) introduced the section C "Applied inorganic and coordination chemistry" by communicating Spin crossover phenomenon at the nanoscale: from fundamental questions towards applications. Finally, the section D "Complexes in the human medicine and in the environment" was guaranteed by Prof. Georgios Psomas (Greece) speaking in his plenary lecture about Coordination compounds of non-steroidal anti-inflammatory drugs: structure and biological activity.

At the previous ICCBIC conference the granting of Ján Gažo Award has been established, which comprises of the Ján Gažo Medal and the certificate of Slovak Chemical Society. The 2019 prize was awarded to Prof. Milan Melník

Peter Segla

peter.segla@stuba.sk

1 Department of Inorganic Chemistry, Faculty of Chemical and Food Technology, Slovak University of Technology, Radlinského 9, 81237 Bratislava, Slovakia

2 Department of Physical Chemistry, Faculty of Chemical and Food Technology, Slovak University of Technology, Radlinského 9, 81237 Bratislava, Slovakia for his considerable contribution to the knowledge of coordination compounds of copper with bioactive ligands, especially the nonsteroidal antirheumatoid and antituberculosis drugs.

Traditional output of ICCBIC conference is the monograph. The current 14th volume bears the name "Progressive Trends in Coordination, Bioinorganic and Applied Inorganic Chemistry" and consists of 12 original peer-reviewed contributions covering all four areas of the XXVII. ICCBIC.

As the organizers, we feel always very pleased and committed when we receive a feedback as that of Prof. Pál Sípos (Hungary):

We returned home with fully recharged batteries and both the "elders" and the students gained very important experience both scientifically and socially.

The next conference XXVIII. ICCBIC will be held on June 6-June 11, 2021, back at the lovely Smolenice castle. We look forward to meet you there.

\section{Special issue of Chemical Papers}

Since 2015, Chemical Papers dedicate one special issue to the original works from participants of ICCBIC conference. One can thus easily get a picture of the spirit of this traditional conference. In total, eight contributions have been submitted to present special issue which is devoted to XXVII. ICCBIC.

Abe and coworkers studied synthesis, structures, and solid-state thermochromic dual emission in visible and nearinfrared regions for tetra- and hexanuclear $\mathrm{Cu}(\mathrm{I})$ iminothiolate complexes.

Bortoluzzi and coworkers reported preparation and characterization of two novel neutral palladium(II) and platinum(II) chlorido-complexes which are expected to show different physical and chemical properties with regard to analogous species. In their work ${ }^{1} \mathrm{H}$ NMR spectroscopy, $\mathrm{X}$-ray spectroscopy and DFT calculations were employed. 


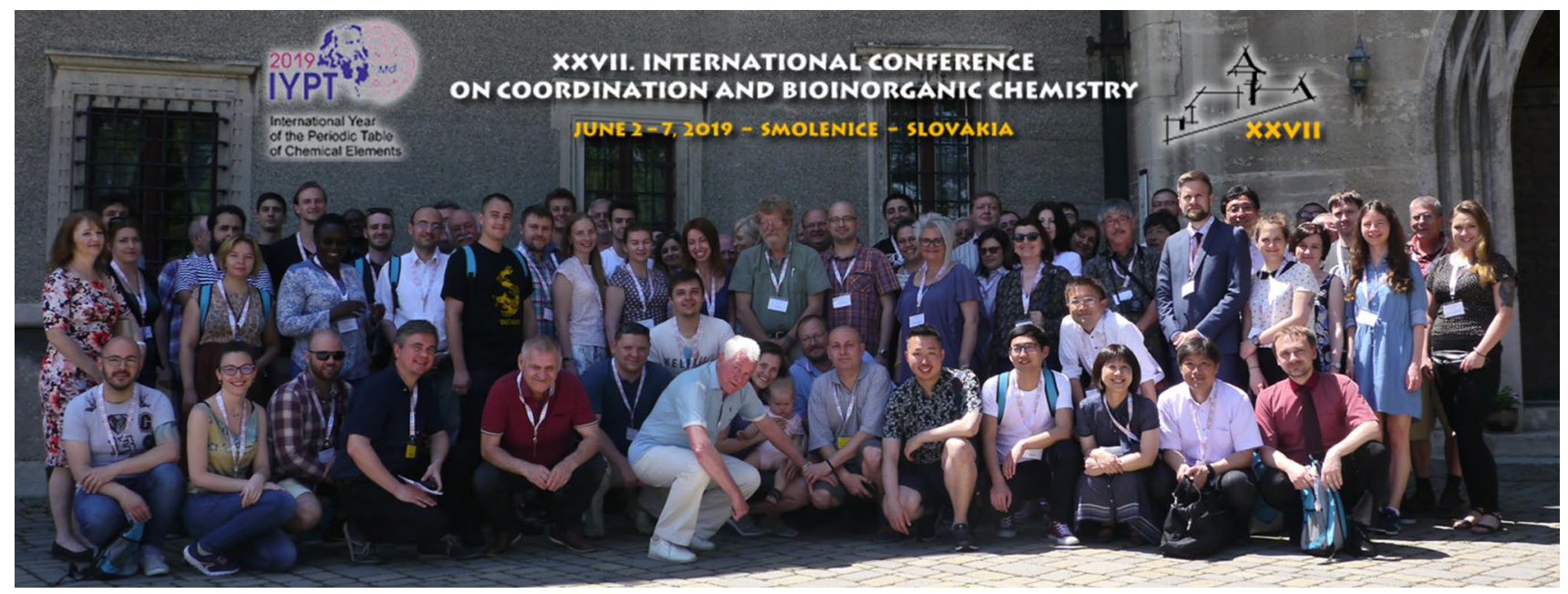

Fig. 1 Participants of XXVII. ICCBIC

In the second work from Bortoluzzi and coworkers, luminescence of phosphoramide and arylphosphonic diamide complexes of $\mathrm{Eu}(\mathrm{III}), \mathrm{Tb}(\mathrm{III})$, and $\mathrm{Gd}(\mathrm{III})$ were studied. The electronic features of the ligand were shown to deeply influence the possibility of energy transfer towards the central atoms.

Brezovan and coworkers presented four novel Co(II) succinate polymers, out of which one possesses rare tetrahedral coordination environment of the central atom which correlates with its spin-only magnetism. The other three systems were octahedral, leaving thus magnetic angular momentum unquenched. The experimental results were confronted with state-of-the-art ab-initio calculations.

Jozefíková and coworkers introduced synthesis and detailed characterization of six novel copper(II) 2-chloronicotinato complexes and studied their hydrogen-bonding supramolecular motifs by modern Hirshfeld surface analysis. Three different coordination motifs around central atom were documented and agreement with EPR spectra was concluded.

Mazúr and coworkers studied temperature induced spin crossover in a previously prepared Fe(III) complex by temperature dependent Q-band and X-band EPR spectroscopy. Their findings are in agreement with previous magnetic measurements showing thus the viability of presented uncommon approach.

Nyawade and coworkers synthesized three novel Pd(II) complexes with tridentate ligands coordinated to the central atom via pyrrole nitrogen atom. Two of these systems showed good antimicrobial activity against six tested bacterial species.

Finally, Ondrejovič and coworkers studied complexes with tetrahedral structural motif $\mathrm{Cu}_{4} \mathrm{O}$ using the Hirshfeld analysis and vector analysis. Vector calculations applied usually to mechanical and electrical macroconstructions are here applied to microconstructions represented by structures of $\mathrm{Cu}_{4} \mathrm{OX}_{6} \mathrm{~L}_{4}$ molecules.

Publisher's Note Springer Nature remains neutral with regard to jurisdictional claims in published maps and institutional affiliations. 